\title{
Bilateral Ovarian Torsion during Follow-up for Antenatally Detected Ovarian Cysts
}

\author{
Bozidar Zupancic, ${ }^{1}$ Marko Baskovic, ${ }^{1 *}$ Ljudevit Sovic, ${ }^{1}$ Dubravko Habek² \\ 1 Department of Pediatric Surgery, Children's Hospital Zagreb, Croatia \\ 2 Department of Gynecology and Obstetrics, University Hospital Sveti Duh, Croatia
}

\begin{abstract}
Ovarian torsion is a surgical emergency demanding timely diagnosis and treatment to prevent loss of the ovaries which if happens may result in functional and emotional consequences. Simple (less than $5 \mathrm{~cm}$ in size) ovarian cysts require follow-up for potential self-resolution. We describe a case of antenatally detected bilateral ovarian cysts that developed bilateral ovarian torsions on follow-up, postnatally.
\end{abstract}

\section{Key words: Ovarian cyst; Antenatal diagnosis; Ovarian torsion}

Correspondence*: Marko Baskovic, Department of Pediatric Surgery, Children's Hospital Zagreb, Croatia
$\begin{array}{ll}\text { E-mail: baskovic.marko@gmail.com } & \text { C } 2017 \text {, Zupancic et al. } \\ \text { Submitted: } 07-03-2017 & \text { Accepted: } 17-03-2017 \\ \text { Conflict of Interest: None } & \text { Source of Support: Nil }\end{array}$

This is an open-access article distributed under the terms of the Creative Commons Attribution License, which permits unrestricted use, distribution, and reproduction in any medium, provided the original work is properly cited.

\section{INTRODUCTION}

Antenatally detected ovarian cysts can be classified into simple and complex cysts. Simple ovarian cysts with size less than $5 \mathrm{~cm}$ can resolve itself over few weeks to months postnatally, owing to decrease in levels of maternal hormones in patient's blood. Complex cysts or ovarian cysts with size more than $5 \mathrm{~cm}$ are usually dealt surgically to avoid gonadal loss.[1] We report a patient in whom drastic complication occurred while patient was under follow up.

\section{CASE REPORT}

A female newborn, product of a twin pregnancy (36.5 weeks of gestation), was discharged on10th day after the birth for follow-up due on antenatally detected bilateral ovarian cysts (size less than $5 \mathrm{~cm}$ ). On follow-up at the age of 2 months, pelvic ultrasound showed right ovary $37 \times 27 \times 35 \mathrm{~mm}$ in size and left ovary $29 \times 32 \times 50 \mathrm{~mm}$ size filled with echogenic content with intraluminal septa and normal circulation on Doppler ultrasound. Tumor markers done were reported as $\beta$-HCG $1.4 \mathrm{IU} / \mathrm{L}$ and alpha fetoprotein $732.9 \mathrm{ng} / \mathrm{mL}$. Patient was advised for regular follow-up. Due to vague unrest of infant and suspected signs of acute abdominal pain, twenty days after discharge, the infant was readmitted. Ultrasound findings suggested bilateral adnexal torsion without detectible blood flow on Doppler ultrasound. Emergent exploration showed the left ovary of approximately $5 \mathrm{~cm}$ in diameter, twisted by 720 degrees and the right ovary twisted around its axis by 720 degrees both were of dark brown in color. The right ovary with its stem was wrapped around the left fallopian tube (Fig.1). Initially, detorsion of both ovaries was done. After half an hour of waiting and applying warm packs, ovaries appeared gangrenous, except for a small segment of left ovary. Considering the intraoperative findings right-sided adnexectomy and left-sided partial oophorectomy was done leaving $0.5 \mathrm{~cm} 2$ of ovarian tissue behind. Histopathology findings reported cysts with tissue structure barely discernible due to coagulation necrosis. On third postoperative day, re-laparotomy and intestinal adhesiolysis was done 
owing to early postoperative intestinal obstruction. The residual ovarian tissue looked normal. Postoperative course was uneventful this time. Three years after surgery, ultrasound of residual ovarian tissue shows a typical echo-structure of the ovary $12 \times 10 \mathrm{~mm}$ with detectable flow in adnexal pedicle.

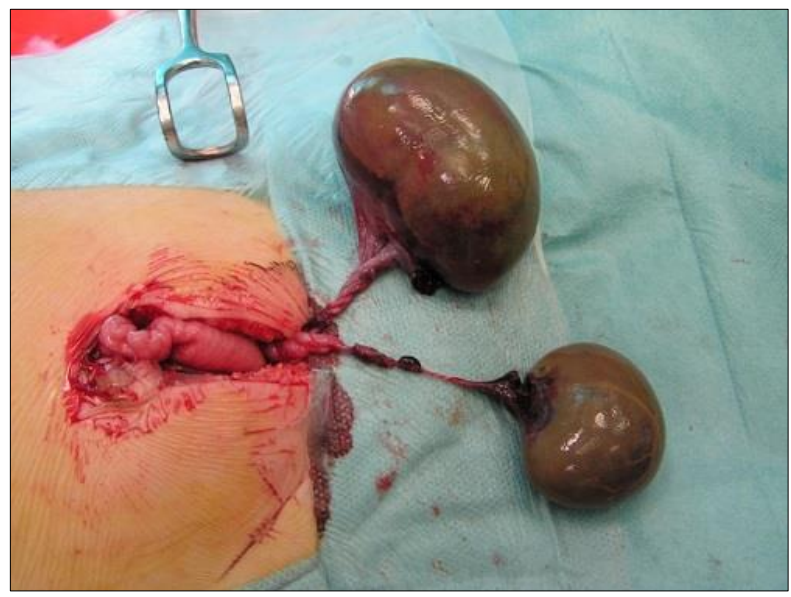

Figure 1: Bilateral ovarian torsion with adnexal entanglement.

\section{DISCUSSION}

Few reports described ovarian torsion during intrauterine period with simple cysts of size less than $5 \mathrm{~cm}$. Our patient was in follow up for self resolution of ovarian cyst however, she developed torsion. If symptoms were picked up early, a prompt surgical intervention would have saved the ovaries, though a small portion of left ovary remained intact and is growing on follow-up scans.

In our case, both ovaries not only had multiple twists around their axes, but also these ovaries were wrapped around each other. Only few cases of ovarian entanglement have been reported in literature.[2-5] Enlarged cysts with the elongation of both adnexal ligaments may be the possible explanation for the torsion and entanglement. Possibility of torsion in small sized simple ovarian cyst must be kept in mind in patients who are on follow up for spontaneous resolution and same must be told to the parents.

\section{REFERENCES}

1. Bagolan $\mathrm{P}$, Giorlandino $\mathrm{C}$, Nahom A, Bilancioni E, Trucchi A, Gatti C, et al. The management of fetal ovarian cysts. J Pediatr Surg. 2002;37:25-30.

2. Child TJ, Watson NR, Ledger WL. Sequential bilateral adnexal torsion after a single cycle of gonadotropin ovulation induction with intrauterine insemination. Fertil Steril. 1997;67:573-5.

3. Bilder D, Goldenberg M, Ben-Rafael Z, Oelsner G. Bilateral adnexal torsion after clomiphene citrate therapy. Hum Reprod. 191;6:1443-4.

4. Frank M, Neeman O, Halperin R, Schneider D, Herman A, Pansky M. Simultaneous bilateral torsion and entanglement of the adnexa. JSLS. 2006;10:520-1.

5. Boettcher M, Kanellos-Becker I, Akkurt I, Reinshagen K. Concomitant bilateral adnexal entanglement in a 7-year-old girl with precocious puberty. Int J Gynecol Obstet. 2013;123:248-9. 